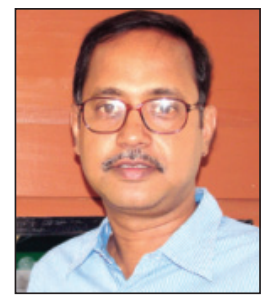

INDIAN JOURNAL OF POWER \& RIVER VALLEY DEVELOPMENT www.ijprvd.info

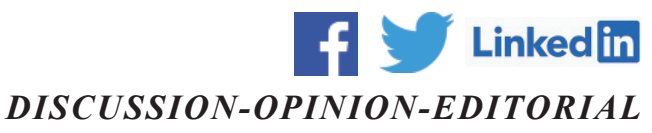

Jayanta Bhattacharya

\title{
To reduce bird and bat deaths by wind turbines
}

The U.S. Fish and Wildlife Service estimates that between 140,000 and 500,000 bird deaths occur at wind farms each year. The most significant threat is posed to species of large, threatened and high-conservation-value birds including famous golden and bald eagles. Since large birds have much lower reproductive rates than small birds (golden eagles, for example, have just one or two chicks in a brood less than once a year), their deaths have a far greater impact on the overall population of the species.

Wind turbines have also been found to be one of the leading causes of mass bat mortality-with some studies pinning fatalities at 888,000 bats a year. "Unprecedented numbers of migratory bats are found dead beneath industrial-scale wind turbines during late summer and autumn in both North America and Europe," says Paul Cryan, a research biologist with the U.S. Geological Survey. "There are no other well-documented threats to populations of migratory tree bats that cause mortality of similar magnitude to that observed at wind turbines." Bats play an important role in the planet's ecosystems. Not only do the aerial mammals consume hordes of pest insects - they are also instrumental in pollinating flowers and dispersing seeds to regenerate rainforests. In North America, hoary tree bats comprise around 75 per cent of bat species affected by turbines, making up half of all fatalities. According to the journal Biological Conservation, the hoary bat population could be at risk of extinction due to mortality from wind turbines. Like large birds, bats are long-lived mammals with low reproductive potential, requiring high adult survivorship to maintain populations. The widespread fatalities of hoary bats at wind turbines could (literally) cut down the hoary bat population by as much as 90 per cent in the next 50 years.

What are the solutions at hand? Unlike previous years, wind energy companies are now responsible for completing environmental impact assessments (EIAs) prior to the installation of wind turbines in an area. Bird migratory routes are avoided, and vegetation surveys are conducted underneath turbines to ensure that none of the migratory birds' preferred food sources are present. In Spain, some wind energy

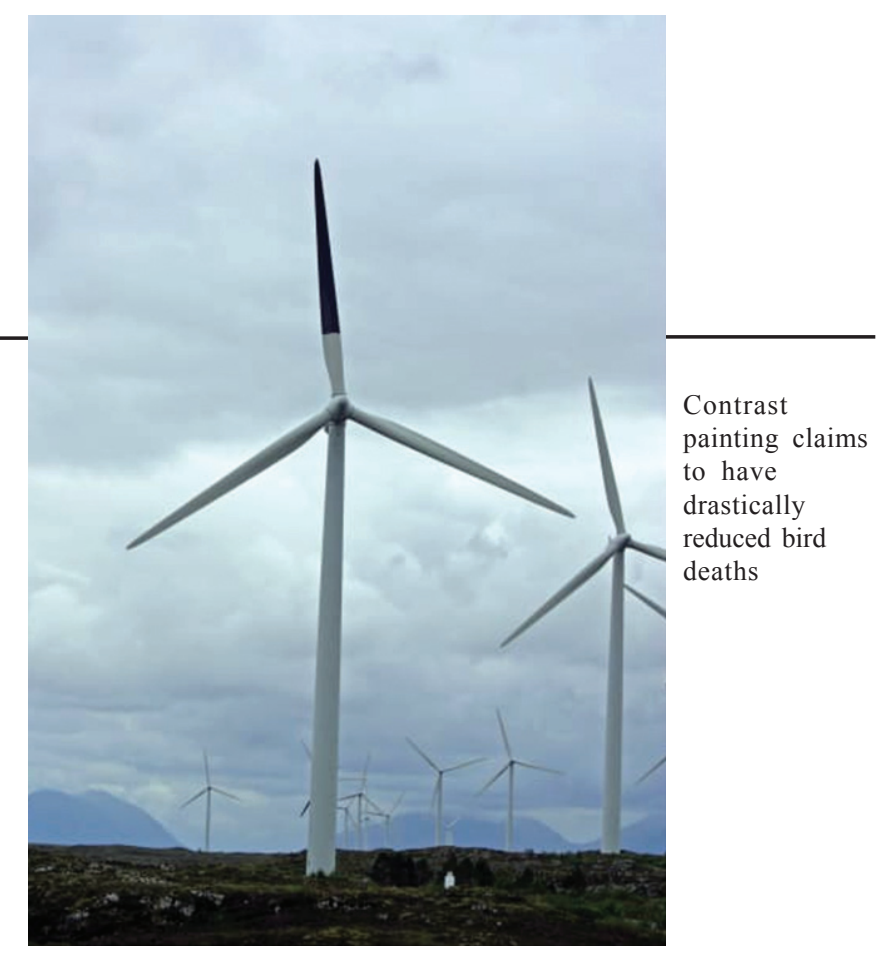

companies even shut down wind farms when large numbers of migrating birds approach. Superficially tilling the soil around the base of wind turbines - making the area less attractive to kestrels due to the consequent reduction of prey around the turbines claimed to have achieved 75-100 per cent decline in collisions over a period of two years. Even more recently, Norwegian scientists have discovered that painting one of the three blades on a wind turbine black reduces avian deaths by 72 per cent.

It is promising that researchers at Texas State University and Bat Conservation International have found an innovative solution to discourage bats from entering wind turbine airspaces: a bat deterrent system that jams bats' echo location capabilities with ultrasound. A bat deterrent system utilizes a set of speakers to produce an ultrasonic acoustic field at a pitch of $20-50 \mathrm{kHz}$ - the same range as bats' natural echolocation frequencies. This interferes with their ability to receive and interpret their own echo location calls and creates an airspace that is difficult to navigate, forcing the bats to give up and leave the area.

A parallel reality. "Saying wind power can only be green if there are no impacts is like saying medicine can only be effective if it has no side effects," says John Anderson, director of siting policy for the American Wind Energy Association. "At some point, we need to put the benefits and risks into context." 